\title{
Fight fire with fire
}

\author{
Can biopesticides fill the void left by banning chemical pesticides and herbicides?
}

$\mathrm{S}$ ince our hunter-gatherer ancestors began to develop agriculture more than 10,000 years ago, farmers have been battling with Nature to protect their cultivated plants against pests and diseases. Organisms from all kingdoms of life-from mammals and insects to bacteria, fungi and viruses-are attracted by the easy pickings that large fields of plants represent, and farmers have sought to contain them by using various strategies, including the earliest, simplest and generally most successful one: crop rotation.

Early farmers also turned to toxic elements-such as sulphur, arsenic and mercury - to fight pests and pathogens, with little awareness of the danger that these toxins presented to humans, let alone to the environment. The advent of organic chemistry eventually led to the development of synthetic compounds - in particular, organochlorine insecticides such as DDT—with initially spectacular successes in the fight against pests. However, over time it became clear that DDT and other organic pesticides are slow to degrade, persist in the environment and accumulate in the fatty tissues of predators, in particular mammals and birds.

In 1962, the American naturalist Rachel Carson (1907-1964) published her landmark book, Silent Spring, in which she detailed the severe effects of organochlorines on humans and the environment; the book not only triggered the environmental movement but also led to subsequent bans on organochlorine pesticides. Over time, the chemical industry has developed other classes of insecticide, including organophosphates and carbonate pesticides, which degrade more quickly. Yet, these have also been restricted by many regulatory agencies because they are even more toxic to humans than are organochlorines.

Inspired in part by Carson's book, interest and investment in biological measures to control pests began during the 1960s. But, for almost two decades, the production and use of biopesticides were largely confined to a cottage industry, with low acceptance from most farmers because of poor efficacy and quality control. In 1981, however, the first applications of genetic engineering represented something of a breakthrough for biopesticides. The cloning of the delta endotoxin-an insecticidal toxin-produced by the widespread soil bacterium Bacillus thuringiensis (Bt), and its subsequent expression in and purification from Escherichia coli, allowed the large-scale production and use of this highly efficient pesticide (Schnepf \& Whiteley, 1981). The ability to express the toxin in other organisms, as well as modifications made to the bacteria themselves, opened the door to large-scale production of various biopesticides and attracted large agrochemical companies.

$\mathrm{H}$ owever, genetically engineered biopesticides turned out to be something of a false dawn because the very factors that made them environmentally attractive-in particular, their toxicity to a limited range of target organisms-ultimately limited the market's acceptance of them and large biotechnology companies subsequently withdrew from the field. Even the success of the engineered Bt toxin was something of a poisoned chalice for biopesticides: it was so successful that the endotoxin gene was soon transferred into two main crops - cotton and wheat-so that the plants could express the insecticidal proteins themselves-thus negating the need to deliver and apply the Bt pesticide-which created a

...66 years after DDT was first
commercially produced, pests-
particularly insects—continue
to have a major toll on agricultural
production

fast-growing market for genetically modified (GM) pest-resistant plants.

Meanwhile, some of the most effective synthetic chemicals to be used as pesticides in agriculture have been banned owing to their non-specific toxicity or environmental impact. Moreover, as Dave Chandler, a senior researcher at the University of Warwick (UK) who specializes in microbe-invertebrate interactions, pointed out: "There are over 500 arthropod pest species with resistance to one or more chemical pesticides now," which means that even many of the synthetic products still available for use are less effective than they used to be.

The result is that, 66 years after DDT was first commercially produced, pests-particularly insects - continue to take a major toll on agricultural production. In India, for example, around $18 \%$ of the total crop yield is still lost to pests each year (Anon, 2007). In this regard, further bans on agrochemicals being considered by US and EU regulators might be cause for concern, according to a recent report for the European Parliament's Committee on Agriculture and Rural Development. The report found that, in the worst case, the impact of banning many of the remaining effective chemical pesticides might mean that the "European agricultural economy and related upstream and downstream industries will wither and Europe will become a net importer of agricultural products, while consumers will not have secured access to reasonable 'price, choice and quality of food'" (Theodoris, 2008).

So-called 'cut-off' criteria, which assess a range of environmental and health impacts of synthetic pesticides, are also resulting in bans in the USA. In addition, the new administration is likely to be more supportive of biopesticides than its predecessor, according to Lawrence Lacey, biopesticides advisor to the US Department of Agriculture. "President [Barack] Obama has already reversed some 
of the environmentally unfriendly laws of the Bush administration," Lacey commented. "With azinphos-methyl and other broad spectrum pesticides on the chopping block, I believe the regulators and lawmakers will see the writing on the wall—at least the liberal majority will."

Even before President Obama's election, the biopesticide field had been gradually gathering momentum, particularly in light of an equally slow decline in the use of conventional chemical pesticides, according to insect pathologist David Grzywacz, from the Natural Resources Institute at the University of Greenwich (London, UK). "The biocontrol industry has seen modest growth, maybe $2 \%$ per annum, which, while not spectacular, is in contrast to the recent trend showing a steady $1 \%-2 \%$ per annum fall in the synthetic chemical market," he noted.

Y et, there is some confusion about what exactly constitutes a 'biocontrol' agent. At present, many authorities, including some regulators, use this umbrella term to include pheromones and various plant extracts, tending to count higher organisms such as predatory insects as falling outside their jurisdiction. By contrast, Grzywacz considers that only microbial agents - in particular viruses, bacteria, microfungi and nematodes-should qualify as biopesticides. Chandler, meanwhile, contends that biopesticides should be defined more by their mode of use, involving an 'inundative strategy', related to, but distinct from, the way in which synthetic chemicals are used. "These products are applied in 'large' quantities to the pest arena," he said, "meaning at significantly higher concentrations than occur in nature." Furthermore, Chandler commented that the agents should be commercial products and immediately effective, rather than having to rely on subsequent reproduction of the agent within the pest population —as would be necessary for an insect-based biocontrol agent-although such reproduction might also be helpful in establishing sustainable pest control.

But, in the biological world, things are rarely clear-cut and any adopted definition of biocontrol is likely to be blurred at the edges. For example, Chandler noted that some microorganisms are being used as adjuvants in plants to stimulate natural immune responses and increase resistance to various pathogens. $\mathrm{He}$ also pointed out that fungi that are pathogenic to insects can colonize plants and confer on them resistance to insect pests.
T here is also the controversial question of whether GM crops engineered for resistance such as Bt cotton and wheat, should be considered as examples of biocontrol. For the organic farming movement, the inclusion of GM crops under the banner of biocontrol is not appropriate, as organic farmers have a need for sustainable methods of pest control that do not contravene the rules or indeed the spirit of their enterprise. Rightly or wrongly, the GM label is taboo, although Emma Hockbridge, a policy campaigner for the Soil Association (Edinburgh, UK), pointed out that organic farmers have cautiously embraced several biopesticides.

The Soil Association sets standards for certifying organic food and drink products in the UK; "We take individual products on a case-by-case basis, and we do allow a number of biological controls within Soil Association organic standards, such as Japanese EM [Effective Microorganisms]," Hockbridge commented. EM is a formulation of organisms composed of phototrophic bacteria, lactic acid bacteria and yeast produced by natural anaerobic fermentation. When this mix is inoculated into plants, EM can protect the crop against infection by other microorganisms. Other bacteria can also be used to provide blanket protection of the soil, or rhizosphere, against rot-infecting microfungi. Several bacteria have been shown to protect ground nuts against collar rot disease, for example (Kishore et al, 2005), which eats away at the crown of the plant and can also affect other trees such as the apple. Of course, this type of systemic protection can also operate in the other direction; microfungi can confer protection against pathogenic bacteria or even undesirable plants.

Indeed, the development of biological herbicidal products has been focused on the exploitation of microfungi, as these cause more plant disease than any other microorganisms and this pathogenicity can be used against weed plants. These genetically altered organisms are known as mycoherbicides and are highly specific, genetically stable and can be readily cultured for mass production. Moreover, they usually decline to low population levels when the target weed has been removed from the site and thus do not become a problem themselves. The first commercially available mycoherbicide was DeVine ${ }^{\circledR}$, which was originally developed and released in 1981 by Valent BioSciences Corporation (Libertyville, IL, USA) to control strangle vine in citrus groves in the USA. However, mycoherbicides have not yet enjoyed huge commercial success; they have actually attracted more attention for their possible use against a different type of pest, namely, crops of illegal drugs grown in Columbia and other South American countries (Anon, 2004).

From the point of view of a plant, it is obviously not ideal to pit microorganisms against each other and exploit their natural chemical warfare as a crude form of self-defence. Equally, plants have not been hanging around waiting for humans to keep them pathogen free; they have evolved their own antimicrobial compounds. In some cases, the same compounds provide broad protection for the plant against both bacteria and fungi. For example, a lysozyme isolated from the mung bean (Phaseolus mungo) has both antifungal and antibacterial activity (Wang et al, 2005), and there is growing interest in exploiting such plant extracts as biopesticides.

S o far, however, biological control agents have been most widely used against insect pests. In 1993, Certis USA (Columbia, MD, USA), one of the world's largest biopesticide production and distribution firms, began trials of a biological insecticide called CYD-X for use against the codling moth (Cydia pomonella). The larvae of the moth are major pests of apple and pear trees, and CYD-X contains a granulovirus that infects and kills them. According to Mike Dimock, Director of Field Development and Technical Services at Certis USA, initial interest in CYD-X came almost exclusively from organic apple growers, who essentially had no effective alternative to Certis' technology if they wished to fight the maggots and remain organic. More recently, however, conventional fruit growers have also turned to CYD-X to deal with the moth for various reasons: "There is resistance to organophosphates, and growers have to follow more governmental regulations, with residue issues for exported fruit," Dimock commented. "All of these things make CYD-X an attractive choice for conventional growers." He also pointed out that CYD-X has been widely adopted as part of integrated pest management (IPM) programmes by apple growers in central Europe, and is used together with naturally derived pheromones to disrupt mating.

Meanwhile, other biopesticides have also emerged for use alongside CYD-X in IPM strategies against a range of pests, 
including the codling moth. The spinosad class of insecticides, for example, which are derived from the rare soil bacterium Saccharopolyspora spinos, complement the use of granulovirus-based insecticides as they attack the adult insects rather than the larvae. The efficacy of this type of combination was shown in a recent study (Arthurs et al, 2007), which also established that the insecticides are highly specific and do not harm non-target species. This result is in line with the general objective of IPM, which is to develop more sustainable pest control strategies that leave little toxic residue and do not harm beneficial organisms.

Yet, according to Mark Goettel, an insect pathologist in the Integrated Pest Management group at the Lethbridge Research Centre (Lethbridge, AB, Canada), some biopesticides still fail to meet organic guidelines. "What makes many biopesticides incompatible with organic farming is that many are 'formulated' with additives [...] to increase shelf life, ease of application, and so on" Goettel said. "For instance, BotaniGard [which is based on a fungus that attacks aphids] is formulated with paraffinic oils and emulsifiers, which are not acceptable for [use in] organic farming. Consequently, the company [BioWorks; Fairport, NY, USA] had to develop and re-register a specific product that satisfied organic farming by using vegetable oils in their formulation."

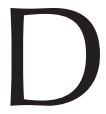

ave Moore, senior researcher in invasive pest management at the non-profit Centre for Agricultural Bioscience International (CABI; Wallington, Oxford, UK), suggested that organic farming is increasingly embracing biopesticides, particularly in the developing countries of Africa and newly industrialized ones such as China and India. "In many parts of the world biopesticides are accepted easily, where available, and are seen as totally compatible with organic," he said. He cited the example of Green Muscle $^{\circledR}$, an insecticide resulting from an international research consortium called LUBILOSA (Biological Control of Locusts and Grasshoppers; Pinetown, South Africa), as an example of a biopesticide that has been adopted in Africa. Green Muscle is based on the naturally occurring fungus Metarhizium anisopliae, which is toxic to locusts and grasshoppers, and is having a big impact against these pests. Moreover, Green Muscle is not toxic to farmers, or other insect or animal species, which is particularly important. As Moore pointed out, the current

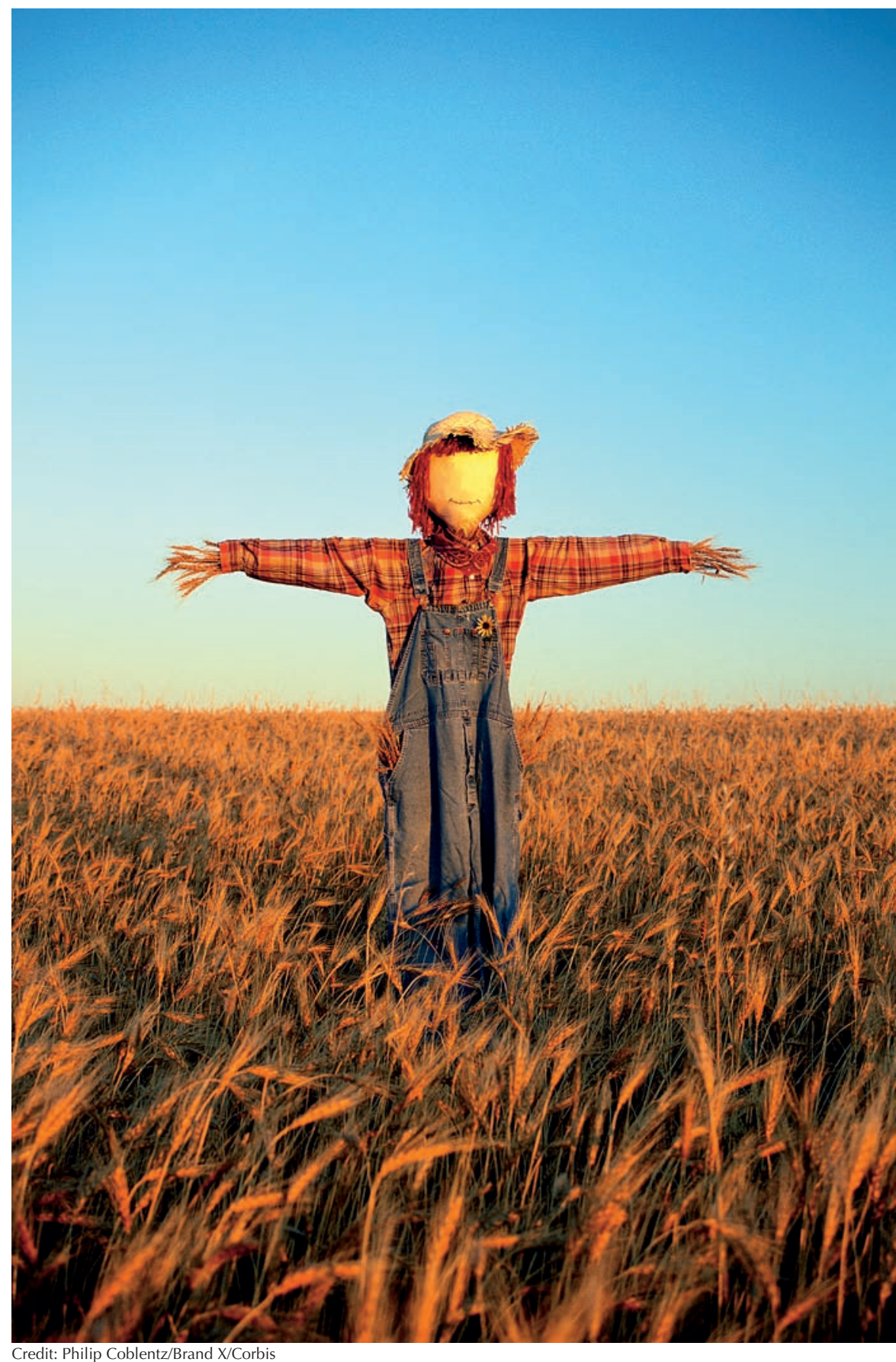

practice of excessive chemical spraying to combat pests in Africa damages the flora and fauna, as well as the health of poor farmers who cannot afford protective clothing.

In most cases, however, biopesticides have a weaker immediate impact than chemical pesticides, so the question is whether and how they can fill the inevitable void left by banning chemical products. After all, according to Chandler, the biopesticide movement lost its way two decades ago because of a vain attempt to mimic the 'big hit' effect of chemicals: "I think in the past there was something of a naive quest to look for 'magic bullets' for pest control, in much the same way that conventional pesticides were used-and unfortunately GM crops have tended to be treated in the same way," he said. "However, in pest control there is no such thing as a magic bullet-many pests have the natural tendency to evolve resistance to their control agents if these are used 
injudiciously." With this in mind, Chandler argued that several biopesticides ought be used in combination within sustainable IPM strategies, and that we should give up on the idea of the total extermination of pests.

$\mathrm{T}$

he biopesticide market must attract investment from larger biotechnology companies if biopesticides are to finally replace chemicals. This will mean finding organisms that can act as the production base for various related products to control a large number of pests, as well as compatibility with a range of crops. According to Lacey, nucleopolyhedral viruses have great potential in this regard, as they are able to infect many insect pests and protect a broad range of hosts, which has raised hopes of providing broad-spectrum protection.

This change of attitude-away from a single chemical silver bullet toward continuous IPM strategies that establish populations of protective organisms to provide 'chronic toxicity' against pests of all types - is the common thread that links the diverse range of current biopesticide products and organisms. For the foreseeable future, however, there will still be a need for the use of chemical pesticides to tackle occasional acute pest outbreaks, against which biopesticides are still ineffective.

\section{REFERENCES}

Anon (2004) The Re-emergence of the Biological War on Drugs. TNI Drug Policy Briefing May 7. Amsterdam, The Netherlands: Transnational Institute, www.tni.org

Anon (2007) Report on Indian Pesticide Industry. Mumbai, India: Bharat Book Bureau

Arthurs SP, Lacey LA, Miliczky ER (2007)

Evaluation of the codling moth granulovirus and spinosad for codling moth control and impact on non-target species in pear orchards. Biol Control 41: 99-109

Kishore GK, Pande S, Podile AR (2005) Biological control of collar rot disease with broadspectrum antifungal bacteria associated with groundnut. Can J Microbio/ 51: 123-132

Schnepf HE, Whiteley HR (1981) Cloning and expression of the Bacillus thuringiensis crystal protein gene in Escherichia coli. Proc Natl Acad SCi USA 78: 2893-2897

Theodoris P (2008) The Consequences of the 'Cut Off' Criteria for Pesticides: Agronomic and Financial Aspects. Brussels, Belgium: European Parliament

Wang S, Ng TB, Chen T, Lin D, Wu J, Rao P, Ye X (2005) First report of a novel plant lysozyme with both antifungal and antibacterial activities. Biochem Biophys Res Commun 327: 820-827 